\title{
LIBERDADE, DESENVOLVIMENTO SOCIAL E DEMOCRACIA: REFLEXÕES SOBRE O LIVRE MERCADO E LIVRE EXPRESSÃO
}

\section{Adriel Borges Simoni* Ana Claudia Corrêa Zuin Mattos do Amaral ${ }^{* *}$}

Resumo: A liberdade em suas várias irradiações se encontra prevista na Constituição Federal de 1988 como direito fundamental. A liberdade negocial, contudo, é limitada por uma série de normas de natureza cogente e pela atuação direta do Estado no mercado. Do mesmo modo, a liberdade de expressão padece de ameaças de grupos diversos da sociedade. Por intermédio do método teórico via levantamento bibliográfico e de uma abordagem dedutiva, esta pesquisa realça a imprescindibilidade da liberdade econômica e da liberdade de expressão para a consecução do desenvolvimento social e sua íntima ligação com o ideal democrático.

Palavras-chave: Liberdade. Desenvolvimento social. Livre mercado. Livre expressão. Liberalismo.

\section{FREEDOM, SOCIAL DEVOLOPMENT AND DEMOCRACY: REFLECTIONS ON FREE MARKET AND DEMOCRACY FREE SPEECH}

\begin{abstract}
Freedom in its various aspects is provided in the 1988 Federal Constitution as a fundamental right. Negotiating freedom, however, is limited by a series of rules of a cogent nature and by the direct action of the State in the market. In the same way, freedom of expression suffers from threats from different groups in society. Through the theoretical method by a bibliographical survey and a deductive approach, this research highlights the indispensability of economic freedom and freedom of expressions for the achievement of social development and its close connection with democratic ideal.
\end{abstract}

Key-words: Freedom. Social devolopment. Free Market. Freedom of expression. Liberalism.

\section{INTRODUÇÃO}

O poeta português, Fernando Pessoa, rememora nos versos de um de seus poemas a célebre frase que "navegar é preciso, viver não é preciso", homenagem que prestou aos navegadores antigos, mais especificamente ao general romano Pompeu Magno que a teria por primeiro proferido quando se lançou ao mar com sua tripulação em meio a tempestades para garantir a entrega de provisões a Roma, que passava fome diante de uma rebelião de escravos

\footnotetext{
* Mestrando em Direito Negocial pela Universidade Estadual de Londrina (UEL). Especialista em Direito Empresarial pela Universidade Estadual de Londrina (UEL). Advogado. E-mail: adrielsimoni@hotmail.com

${ }^{* *}$ Doutora em Direito Civil Comparado pela PUC/SP. Mestre em Direito Negocial pela Universidade Estadual de Londrina (UEL). Professora e pesquisadora do Programa de Mestrado em Direito Negocial da Universidade Estadual de Londrina (UEL). E-mail: anaclaudiazuin@live.com.
} 
liderada por Espártaco. Após tal feito de tamanha bravura, foi alçado à condição de cônsul e seguidamente veio a compor o que se denominou como o primeiro triunvirato, passando a governar Roma em conjunto com Crasso e Júlio Cesar. A referida frase é paradoxal, mas permite refletir sobre a urgência da liberdade na persecução dos grandes feitos, como o de Pompeu.

Dificilmente outro ideal foi perseguido com mais afinco na história humana do que a liberdade. Tal ideal se reflete em todos os âmbitos, desde o filosófico, como ser livre das próprias vontades na construção de uma vida de virtudes, ser livre das amarras do Estado, ser livre para professar sua fé e seus pensamentos. Prevista em todas as constituições democráticas e em uma série de Convenções internacionais, o direto à liberdade se irradia para diversos âmbitos da existência humana, como a liberdade econômica, pilar do pensamento liberal, para o qual o bem estar e a igualdade são conquistados por meio da liberdade. Outro âmbito deste direito fundamental, tão caro à sociedade, é a liberdade de expressão, essencial na construção de uma sociedade democrática, sobretudo uma tão plural e rica como o Brasil.

Contudo, a presença constante e muitas vezes massiva do Estado no mercado e a existência de uma série de normas de natureza cogente revelam uma ingerência do Estado na vida do particular e acabam por limitar a liberdade negocial dos indivíduos, inaugurando o chamado Estado de bem estar social, que diverge das premissas e métodos utilizados pelo Estado liberal na busca do desenvolvimento social. Também a liberdade de expressão sofre constantes ataques na medida em que a Suprema Corte passa a endossar a censura através da retirada de matérias da rede internacional de computadores constantes em sítios eletrônicos ${ }^{1}$ na tentativa antidemocrática de se imunizar contra o sagrado direito à crítica, ou mesmo quando grupos muitas vezes denominados extremistas religiosos atacam produtoras de conteúdo humorístico que satirizaram seus credos.

Este artigo tem como propósito realizar a reflexão sobre a imprescindibilidade da liberdade econômica e da liberdade de expressão para alcançar um dos objetivos traçados pela República: garantir o desenvolvimento social. Para tanto, realizar-se-á uma pesquisa

\footnotetext{
${ }^{1}$ No âmbito de um inquérito que intencionava apurar fake news e divulgação de mensagens que atentava contra a honra de ministros da Suprema Corte, o ministro Alexandre de Moraes, do Supremo Tribunal Federal, determinou a retirada do ar dos sítios eletrônicos "O Antagonista" e da revista "Crusoé" que realizavam menção ao então presidente da corte, Dias Toffoli, feita pelo delator Marcelo Odebrecht. Disponível em: <https://www1.folha.uol.com.br/poder/2019/04/ministro-do-stf-censura-sites-e-manda-tirar-do-ar-reportagemsobre-toffoli.shtml>, Acesso em 05 fev. 2021.
} 
bibliográfica e uma abordagem dedutiva para demonstrar a essencialidade de tal direito na consecução do fim almejado e precípuo da Magna Carta.

\title{
2. BREVES CONTORNOS SOBRE A LIBERDADE
}

A liberdade se caracteriza morfologicamente como um substantivo feminino, conceituando-se do ponto de vista semântico como "nível de total e legítima autonomia que representa o ideal maior de um cidadão, de um povo ou de um país" (LIBERDADE, 2021). Em nome deste ideal guerras foram travadas, poemas e canções foram criadas e, claro, inúmeros conceitos filosóficos e políticos foram tecidos ao largo da história da humanidade.

Ao conceber as relações humanas como conflituosas e o homem como um ser essencialmente mau, lobo de si próprio, no Leviatã, o filósofo inglês definiu a liberdade como "a ausência de empecilhos externos, que podem, muitas vezes, tirar parte do poder de cada um de agir como quiser, mas não impedir que cada pessoa use o poder restante de acordo com seu julgamento e razão" (HOBBES, 2012, p. 107). Tal elaboração conceitual hobbesiana aborda a liberdade de uma dimensão individual, ou seja, do ser humano em si considerado, ante a inexistência de constrangimentos alheios à sua vontade.

No plano político a liberdade do homem foi tratada por John Locke (1998, p. 401), para quem esta se constituiria na possibilidade de seguir sua própria vontade em tudo aquilo que não contrariasse uma regra pré-estabelecida de forma consensual a qual o indivíduo consensualmente se submete enquanto parte integrante da sociedade:

\begin{abstract}
A liberdade do homem em sociedade consiste em não estar sujeito a outro poder legislativo além do estabelecido por consenso no Estado, nem ao domínio de outra vontade ou à limitação de outra lei além da que esse poder legislativo tiver estabelecido de acordo com a confiança nesse depositada [...] Mas a liberdade de um homem sob um governo consiste em viver segundo uma regra permanente, comum a todos nessa sociedade e elaborada pelo poder legislativo nela erigido: liberdade de seguir minha própria vontade em tudo quanto escapa à prescrição da regra e de não estar sujeito à vontade inconstante, incerta, desconhecida e arbitrária de outro homem (LOCKE, 1998, p. 401-403).
\end{abstract}

Ainda no campo político, é célebre a construção do chamado pacto social por Jean Jacques Rosseau (2003, p. 32), a qual pode ser sintetizada pela ideia de que o homem, como único meio para se proteger contra as forças que no estado de natureza iria encontrar, buscou uma forma de associação que protegesse as pessoas e os bens de cada um dos integrantes do 
corpo coletivo. Diferentemente de Thomas Hobbes, Jean Jacques Rousseau não entendia que a coação legal imposta a qualquer indivíduo que discordasse de uma lei significasse restrição à sua liberdade, eis que tal coação estaria de acordo com o pacto inicial que haveria substituído a vontade individual pela vontade geral. ${ }^{2}$

A Constituição Federal de 1988 trata da liberdade como um direito fundamental (Art. $5^{\circ}, c a p u t$ ), com inúmeros reflexos como a liberdade de consciência e de crença, liberdade de associação, liberdade de expressão, liberdades artísticas, liberdade de imprensa, liberdade de iniciativa, entre tantas outras onde esse direito fundamental irradia seus efeitos, no campo privado ou público. Nesse ponto, cumpre anotar que a Constituição tem como um dos seus fundamentos a dignidade da pessoa humana, princípio jurídico fruto da reconstrução moral adotada após a segunda guerra mundial. Fundamentando em bases kantianas, há autores que procuram desvendar quais seriam os componentes da dignidade da pessoa humana, conceituando a autonomia como um deles e a diferindo da liberdade:

\begin{abstract}
Note-se que no sistema moral kantiano a autonomia é a vontade que não sofre influências heterônomas e corresponde à ideia de liberdade. Contudo, na prática política e na vida social, a vontade individual é restringida pelo direito e pelos costumes e normas sociais. Desse modo, ai contrário da autonomia moral, a autonomia pessoal, embora esteja na origem da liberdade, corresponde apenas ao seu núcleo essencial. A liberdade tem um alcance mais amplo, que pode ser limitado por forças externas legítimas. Mas a autonomia é a parte da liberdade que não pode ser suprimida por interferências sociais ou estatais por abranger decisões pessoais básicas, como as escolhas relacionadas com a religião, relacionamentos pessoais, profissão e concepções políticas, entre outras (BARROSO, 2016, p. 82).
\end{abstract}

A doutrina, sob uma perspectiva histórica, busca agrupar os direitos fundamentais em diferentes dimensões ou gerações, de modo que a liberdade estaria inserida nos chamados direitos de primeira geração, frutos do triunfo das revoluções liberais do final do século XVIII. Tais liberdades, por se tratarem de uma resistência frente ao Estado, apontam por uma autonomia do indivíduo em face do poder estatal, do qual se exige a não interferência na vida social, pessoal e econômica do indivíduo. Os direitos de segunda geração correspondem àqueles que se prestam a garantir uma igualdade material, exigindo-se do Estado uma participação mais ativa de modo a garantir o exercício desses direitos. Por fim, a os chamados direitos de terceira geração se ligam mais na ideia de solidariedade e fraternidade, como

\footnotetext{
${ }^{2}$ Observa Jean Jacques Rousseau que (2003, p. 32) "Encontrar uma forma de associação que defenda e proteja a pessoa e os bens de cada associado com toda a força comum, e pela qual cada um, unindo-se a todos, só obedece contudo a si mesmo, permanecendo assim tão livre quanto antes. Esse, o problema fundamental cuja solução o contrato social oferece."
} 
direitos transindividuais. Vale anotar que a alusão a sucessivas gerações de direitos fundamentais não implica na anulação de uns direitos pelos outros, pois "o reconhecimento progressivo de novos direitos fundamentais tem o caráter de um processo cumulativo, de complementaridade, e não de alternância" (SARLET, 2001, p. 53).

Em que pesem tais afirmações, existe uma tensão entre a liberdade e os demais direitos fundamentais, as quais ora serão supridas por um sistema de ponderação judicial na apreciação de um caso concreto, ora por escolhas políticas legislativas ou executivas (sujeitas, naturalmente, ao controle judicial). Nas páginas que se seguirão, procurar-se-á analisar a liberdade de expressão e a liberdade econômica configurando-a como pressuposto e fundamento para o desenvolvimento social e da própria democracia.

\section{CONEXÕES LÓGICAS ENTRE LIBERDADE ECONÔMICA E DESENVOLVIMENTO SOCIAL}

As revoluções liberais do fim do século XIX alçaram o princípio da autonomia da vontade como um dos fundamentos da vida civil, tornando ilegítima a intervenção estatal nas relações de cunho econômico dos particulares pois acreditava-se que "que as leis naturais do mercado se encarregavam da promoção do equilíbrio econômico e, por consequência, da harmonia social" (AMARAL; HATOUM; HORITA, 2017, p. 267). Sabe-se que com o advento do Estado Social a chamada autonomia da vontade foi substituída pela autonomia privada, a qual pode ser conceituada como "o poder reconhecido pelo ordenamento jurídico aos particulares, e nos limites traçados pela ordem jurídica, de autorregular os seus interesses estabelecendo certos efeitos aos negócios que pactuam" (COSTA, 2002, p. 614-615). Dessa forma, relativizou-se a liberdade de contratação, de modo que a lei passou a realizar certa ingerência nos contratos particulares com o fim de conferir maior equilíbrio nas relações e persecução de valores de igualdade e solidariedade social, os quais, muitas vezes, já previstos expressamente nas constituições nacionais.

A ingerência em maior ou menor grau do Estado na economia, seja através da criação de cláusulas gerais na lei civil como a função social do contrato e a boa-fé objetiva, seja através da ingerência direta do Estado na economia através do exercício de atividades eminentemente privadas ou serviços públicos, é assunto que desperta debates políticos, 
filosóficos e jurídicos ferrenhos na comunidade, mas parece fato que o desenvolvimento do capitalismo possui ligação direta com a própria liberdade política:

\begin{abstract}
Evidências históricas falam em uníssono sobre a relação de liberdade política e mercado livre. Não conheço nenhum exemplo, no tempo e no espaço, de sociedade que tenha cultivado em grande extensão a liberdade política e que também não tenha praticado algo comparável ao mercado livre para organizar o grosso da sua atividade econômica. Uma vez que vivemos em sociedade livre, tendemos a esquecer como é limitado o âmbito temporal e espacial de algo como liberdade política: a situação típica da humanidade é de tirania, servidão e miséria. O século XIX e o começo do século XX no mundo ocidental se destacam como exceções notáveis na tendência geral da história. A liberdade política, nessas condições, se desenvolveu sem dúvida, em conjunto com a evolução do mercado livre e das instituições capitalistas. Assim também aconteceu na era de ouro da Grécia e nos primórdios do Império Romano. (FRIEDMAN, 2020, p. 12)
\end{abstract}

É importante salientar que para o liberalismo clássico, a ampliação da liberdade é a maneira mais eficaz de promover o bem estar e a igualdade, em detrimento do pensamento de outras linhas teóricas que encaram o bem-estar e a igualdade como pré-requisitos para o exercício da liberdade, sendo certo, porém, que mesmo teóricos que apontem pela maior efetividade de políticas de intervenção e o paternalismo estatal para atingir os fins delineados, ainda que com fortes ressalvas, reconhecem a estreita ligação entre a liberdade econômica e a liberdade política ${ }^{3}$.

Feitas tais anotações, cumpre salientar que a Constituição Federal de 1988 exalta os valores sociais do trabalho e da livre iniciativa como fundamentos do Estado Democrático de Direito $^{4}$, bem como funda a ordem econômica na valorização do trabalho e na livre iniciativa apoiando-se no princípio da livre concorrência ${ }^{5}$. Sabe-se também que a mesma Constituição Federal exalta o pluralismo político como fundamento da República (Art. $\left.1^{\circ}, \mathrm{V}\right)$, a construção de uma sociedade livre, justa e solidária, erradicação da pobreza, bem como a promoção do

\footnotetext{
${ }^{3}$ Conforme enuncia Wolfgang Streek (2012, p. 7) "Essa fórmula implicava essencialmente a aceitação dos mercados capitalistas e os direitos de propriedade pela classe trabalhadora organizada em troca de democracia política, o que lhes possibilitava contar com seguridade social e com a melhoria constante de seu padrão de vida. O período ininterrupto de mais de dois decênios de crescimento resultou em percepções populares, profundamente enraizadas, do contínuo progresso econômico como um direito de cidadania democrática percepções que se converteram em expectativas políticas que os governos se sentiram coagidos a cumprir com a desaceleração do crescimento, mas cada vez menos capazes de cumpri-lo".

${ }^{4}$ Art. $1^{\circ}$ A República Federativa do Brasil, formada pela união indissolúvel dos Estados e Municípios e do Distrito Federal, constitui-se em Estado Democrático de Direito e tem como fundamentos: [...] IV - os valores sociais do trabalho e da livre iniciativa;

${ }^{5}$ Art. 170. A ordem econômica, fundada na valorização do trabalho humano e na livre iniciativa, tem por fim assegurar a todos existência digna, conforme os ditames da justiça social, observados os seguintes princípios: [...] IV - livre concorrência;
} 
bem comum como objetivo fundamental da República (Art. $3^{\circ}$, I, III e IV), além de elencar a redução das desigualdades regionais e sociais e a busca do pleno emprego como princípio geral da ordem econômica (Art. 170, VII e VIII).

Trata-se de fato notório que a divisão do trabalho e a especialização de funções para uso eficaz dos recursos disponíveis é um problema básico de organização social e das atividades econômicas, sendo tal fato visível mesmo em sociedades atrasadas, mas que pode ser observado em maior escala nas sociedades avançadas, que fazem uso da ciência e tecnologia modernas ${ }^{6}$. O debate que envolve o desenvolvimento e a transposição de problemas sociais pode ser enxergado como um processo de ampliação das liberdades substantivas que os indivíduos gozam, ou seja, a liberdade passa a ser não apenas o fim a ser perseguido, mas também um meio fundamental na consecução do desenvolvimento (SEN, 2010 , p. 25), afirmação que pode gerar perplexidade ${ }^{7}$ quando analisado o fato do autor indiano vencedor do Prêmio Nobel de Economia $^{8} 1998$ ter escolhido a liberdade em detrimento de outros direitos ou princípios como vetor para o desenvolvimento.

Há quem anote que o conceito de Estado liberal, concebido aquele que em menor grau interfira nas atividades privadas, teria sido sumariamente superado pelo que se denomina de Estado de bem estar social. Contudo, importante se faz ponderar que mesmo exemplos antes prodigiosos de Estado de bem estar social, como a Suécia, que ostenta uma alta carga tributária e um bom retorno para o pagador de impostos, passaram a gerar questionamentos (GATEHOUSE, 2018) e insatisfação por parte da sua população (BILLNER; LINDBERG;

\footnotetext{
${ }^{6}$ Nesse sentido, Milton Friedman (2020, p. 15). "Literalmente milhões de pessoas participam do fornecimento mútuo do pão de cada dia, para não falar no automóvel de cada ano. O desafio daquele que acredita na liberdade é reconciliar essa interdependência generalizada com a liberdade individual. Basicamente, há apenas duas maneiras de coordenar as atividades econômicas das multidões - uma é a direção central, envolvendo o uso da coerção - a técnica das forças armadas e do estado totalitário moderno. A outra é a cooperação voluntária dos indivíduos - a técnica dos mercados. A possibilidade de coordenação por meio da cooperação voluntária se baseia na proposição elementar - embora frequentemente contestada - de que as duas partes de uma transação econômica com ela se beneficiem, desde que a transação seja voluntária e esclarecida para ambos os lados. Esse tipo de troca, portanto, pode envolver coordenação sem coerção. Modelo operacional de uma sociedade organizada com base em trocas voluntárias é uma economia de troca de livre empresa privada - o que até aqui denominamos capitalismo competitivo."

${ }^{7}$ Tal perplexidade é fruto da indagação de Flávio Pansieri (2016, p. 456) “[...] qual a razão de a liberdade ser eleita como ponto central no processo de desenvolvimento para Sem, e não qualquer outro valor, princípio ou direito, como igualdade, justiça ou mesmo riqueza? Apesar de não se considerar um liberal, a concepção de desenvolvimento pensada por Amartya confere importância crucial a liberdade individual como fator indispensável para a conquista da condição de agente dos indivíduos. Sem considera as liberdades individuais substantivas tão cruciais que reconhece a necessidade de se avaliar o êxito e o grau de desenvolvimento de uma sociedade a partir destas e de sua extensão".

${ }^{8}$ Conforme se pode extrair da matéria jornalística que enumera todos os vencedores do prêmio. Disponível em: $<$ https://economia.estadao.com.br/galerias/geral,conheca-todos-os-vencedores-do-premio-nobel-deeconomia,21786>, Acesso em 15 jan. 2021.
} 
MAGNUSSON, 2018), fato que pode ser, ao menos em parte, explicado com gastos do governo com refugiados (GOODMAN, 2019). Situação parecida vive o Estado francês (CHRISAFIS, 2018), que também passou a questionar o seu Estado de bem estar social ao apresentar uma série de reformas estruturais, especialmente a reforma da previdência (BASSETS, 2020). O que se pretende demonstrar com tais apontamentos é que um Estado mais limitado em suas ações, portanto menos intervencionista, parece ser mais eficiente e torna a economia mais competitiva. Menor intervenção estatal nas relações privadas implica em maior liberdade para os indivíduos, eis que o mercado, por si só, já parece atender uma vasta pauta social, protegendo os menos favorecidos e grupos minoritários de ataques e descrédito da maioria por pautas alheias à própria produtividade:

\footnotetext{
Ninguém que compre pão sabe se o trigo do qual é feito foi cultivado por um comunista ou por um republicano, por um constitucionalista ou por um fascista, por um negro ou por um branco. Isso mostra como os mercados impessoais separam as atividades econômicas de opiniões políticas e resguarda as pessoas de serem discriminadas por motivos irrelevantes à sua produtividade - não importa que essas razões se associem a opiniões ou etnias. Como sugere esse exemplo, os grupos em nossa sociedade com mais interesse em jogo na preservação e no fortalecimento do capitalismo competitivo são as minorias mais suscetíveis de tornar-se objeto da desconfiança e da animosidade da maioria - os negros, os judeus, os estrangeiros, para mencionar apenas os exemplos mais óbvios. Muito paradoxalmente, contudo, os inimigos do mercado livre - os socialistas e os comunistas - foram recrutados, em grande parte, nesses grupos. Em vez de reconhecerem que a existência do mercado os protegeu dos preconceitos, eles incidem no equívoco de atribuir exatamente ao mercado a discriminação residual. (FRIEDMAN, 2020, p. 23)
}

Nesse contexto, portanto, nota-se que a liberdade econômica pode ser encarada como um fundamento para se alcançarem os objetivos traçados pela Carta Magna, inclusive no que diz respeito a construção de uma sociedade livre, justa e solidária, bem como a promoção do bem comum, enfim: trata-se a liberdade econômica como um pressuposto e um fundamento para o desenvolvimento social.

\section{LIBERDADE DE EXPRESSÃO E PROMOÇÃO DA DEMOCRACIA}

A liberdade de expressão também é fruto da conquista histórica das revoluções liberais do século XVIII, A Declaração dos Direitos do Homem e do Cidadão se referia a ela em seu art. 11 como "um dos mais preciosos direitos do homem". Vários textos e convenções internacionais asseguram este direito, como a Declaração dos Direitos Humanos (art. 19); a 
Convenção Interamericana de Direitos Humanos (art. 13) e a Convenção Europeia de Direitos Humanos (art. 10). No Brasil, o período de redemocratização demandava um forte compromisso com a democracia e os direitos sociais e individuais, de modo que a Constituição Federal de 1988 expressava em seu preâmbulo o objetivo de:

[..] instituir um Estado Democrático, destinado a assegurar o exercício dos direitos sociais e individuais, a liberdade, a segurança, o bem estar, o desenvolvimento, a igualdade e a justiça como valores supremos de uma sociedade fraterna, pluralista e sem preconceitos, fundada na harmonia social e comprometida, na ordem interna e internacional, com a solução pacífica de controvérsias [...]

Compromissada com a radical proibição à censura, a Constituição Federal de 1988 elevou a liberdade de expressão a categoria de direito fundamental, como demonstra o art. $5^{\circ 9}$, IV e IX, tendo ratificado a proibição à censura ao tratar no art. $220^{10}$ da "Comunicação Social".

Entre os muitos argumentos jusfilosóficos que embasam a liberdade de expressão, merece destaque aquele que afirma a essencialidade desse direito na busca pela verdade, ou seja, a livre manifestação do pensamento cria condições propícias para o debate e a identificação de ideias verdadeiras e socialmente úteis, assim como o afastamento de ideias nocivas para sociedade ou simplesmente equivocadas. Esta linha argumentativa foi apresentada no século XVII baseada no pressuposto de que no livre confronto de ideias, a verdade sempre triunfaria: "que a verdade e a impostura se digladiem. Quem jamais ouviu dizer que a verdade perdesse num confronto em campo livre e aberto?” (MILTON, 1999, p. 173).

A liberdade de expressão como fundamento para a busca da verdade foi aprofundada e embora se tenha refutado a ideia de que a verdade em qualquer circunstância prevaleceria ${ }^{11}$,

\footnotetext{
${ }^{9}$ Art. $5^{\circ}$ Todos são iguais perante a lei, sem distinção de qualquer natureza, garantindo-se aos brasileiros e aos estrangeiros residentes no País a inviolabilidade do direito à vida, à liberdade, à igualdade, à segurança e à propriedade, nos termos seguintes: [...] IV - é livre a manifestação do pensamento, sendo vedado o anonimato; (...) IX - é livre a expressão da atividade intelectual, artística, científica e de comunicação, independentemente de censura ou licença;

${ }^{10}$ Art. 220. A manifestação do pensamento, a criação, a expressão e a informação, sob qualquer forma, processo ou veículo não sofrerão qualquer restrição, observado o disposto nesta Constituição.

$\S 1^{\circ}$ Nenhuma lei conterá dispositivo que possa constituir embaraço à plena liberdade de informação jornalística em qualquer veículo de comunicação social, observado o disposto no art. $5^{\circ}$, IV, V, X, XIII e XIV.

$\S 2^{\circ}$ É vedada toda e qualquer censura de natureza política, ideológica e artística.

${ }^{11}$ Conforme argumenta John Stuart Mill (2018, p. 67-68): "Mas, de facto, o ditado de que a verdade triunfa sempre sobre a perseguição é uma daquelas falsidades agradáveis que as pessoas repetem entre si até chegarem ao estatuto de lugares-comuns, mas que toda a experiência refuta [...] É apenas vã sentimentalidade pensar que a
} 
defendeu-se com afinco a liberdade de expressão de um ponto de vista utilitarista, também apegado a busca pela verdade:

Mas o mal particular em silenciar a expressão de uma opinião é que constitui um roubo à humanidade; à posteridade, bem como a geração actual; àqueles que discordam da opinião, mais ainda do que àqueles que a sustentam. Se a opinião for correcta, ficarão privados da oportunidade de trocar o erro por verdade; se estiver errada, perdem uma impressão mais clara e viva da verdade, produzida pela confrontação com o erro (MILL, 2018, p. 67).

Trata-se de um valor essencial para a democracia, pois é uma condição para que os cidadãos se façam ouvir pelos seus governantes, seus anseios, pleitos, inconformismos, revestindo-se de instrumento de persuasão e convencimento. Em uma sociedade democrática os cidadãos devem ter o poder de deliberar, de forma direta ou indireta, sobre as pautas de interesse coletivo. Para tanto, o acesso à informação é fundamental para que se possa debater amplamente sobre todos os assuntos, exercendo de forma consciente o direito de escolha de seus representantes e influenciando, de variadas formas, a condução das políticas públicas. Há íntima relação entre a liberdade de expressão e o ideal democrático de participação cívica nas deliberações que interessam a sociedade, contribuindo seu exercício para que se possam identificar os anseios dos diferentes segmentos da sociedade, ainda que conflitantes ou excludentes.

\begin{abstract}
Com vistas a este objetivo, os cidadãos devem ser expostos a todos os lados de um assunto e a todos os tipos de pontos de vista expressos por uma ampla variedade de interlocutores, sem que o governo possa censurar ou restringir ideias sob o pretexto de que sejam inaceitáveis ou perigosas. Ao cidadão, e apenas a ele, cabe avaliar quais opiniões ou pontos de vista são aceitáveis ou válidos para seus objetivos e decisões [...] A ideia de que todos os cidadãos devem ter voz está no cerne do primeiro exemplo histórico de democracia, a democracia ateniense, na qual os cidadãos se reuniam na Acrópole e tinha oportunidade de manifestar o que pensavam acerca dos problemas da cidade-Estado, apresentando seus argumentos e suas sugestões. Acreditava-se que as melhores soluções adviriam do debate amplo e da votação das melhores propostas [...] $\mathrm{O}$ incentivo ao debate não apenas é inerente à democracia, como contribui para o melhor funcionamento desta, na medida em que aponta para a participação popular e para o diálogo público como meios adequados para a formação de valores. (ANDRADE, 2020, p. 68-69)
\end{abstract}

verdade, enquanto verdade, tem um poder que o erro não tem - de prevalecer contra a masmorra e a fogueira [...] A verdadeira vantagem da verdade é a seguinte: quando uma opinião é verdadeira, pode ser extinta uma, duas ou até muitas vezes, mas no decorrer do tempo haverá pessoas que geralmente a redescubram até algum dos seus ressurgimentos calhar numa altura em que, devido a circunstâncias favoráveis, escape a perseguição até ter adquirido ímpeto suficiente para aguentar todas as tentativas subsequentes de a suprimir". 
Naturalmente se pode anotar que um discurso abrangente com finalidade de encontrar ou construir a melhor alternativa após a ponderação de diferentes opiniões possa significar uma abstração utópica, eis que o próprio acesso à informação não é equitativo. Contudo, tais fissuras no sistema não retiram a imprescindibilidade da liberdade de expressão, como se anota:

Se para muitos a liberdade de expressão tem uma dimensão mais forma do que real, sobretudo na comparação com os detentores dos meios de comunicação em massa, não quer dizer que ela não tenha valor, que não seja efetivamente um meio para o exercício das funções soberanas do povo, menos ainda que seja dispensável. Se ela o fosse, ou se alguém assim o entendesse, então seria preciso admitir que a própria democracia é um ideal supérfluo (MARTINS NETO, 2008, p. 51)

No que concerne à liberdade de expressão artística, especificamente o humor, a discussão ganha contornos dramáticos conforme se pode notar por uma série de eventos recentes, como o massacre realizado na sede do periódico satírico francês, o Charlie Hebdo ${ }^{12}$, as bombas lançadas ao grupo humorístico Porta dos Fundos no Brasil ${ }^{13}$ ou a recente tragédia que culminou na decapitação de um professor francês após a exposição de caricaturas do profeta Maomé (PREVIDELLI, 2021). Como bem se sabe, entre as muitas formas de expressão se encontra a arte, que não obstante a imensa dificuldade em encontrar definição que seja universalmente válida e aceita, tem a proteção da Constituição Federal (art. $5^{\circ}$, IX, art. $220, \S 2^{\circ}$ ), gozando de todas as prerrogativas do direito à liberdade de expressão, dentro do qual se insere.

É possível identificar uma crescente valorização do tratamento da cultura e da arte como temas centrais do direito, inclusive no âmbito constitucional. Há, nesse contexto, uma ampliação do domínio da liberdade de expressão que passa a compreender não apenas a opinião, divulgação de fatos, atuação da imprensa e as atividades científicas, mas também as manifestações de natureza artística e cultural (BRANDÃO, 2018, p. 58)

\footnotetext{
${ }^{12}$ Integrantes de um grupo terrorista muçulmano invadiram a sede do jornal satírico Charlie Hebdo em 2015 armados com fuzil de assalto e assassinaram doze pessoas em represália à representação em charges do profeta Maomé. Quatorze pessoas foram julgadas em 2020 e consideradas culpadas pelo atentado. Disponível em: $<$ https://brasil.elpais.com/internacional/2020-12-16/tribunal-condena-a-30-anos-de-prisao-o-principal-acusadodo-ataque-contra-o-charlie-hebdo-em-2015.html>, Acesso em 18 jan. 2021.

${ }^{13} \mathrm{O}$ grupo produziu uma peça humorística, um especial de natal, onde satirizava elementos que são caros à fé cristã. Disponível em: https://www1.folha.uol.com.br/ilustrada/2019/12/sede-do-porta-dos-fundos-sofre-ataquea-bomba-na-vespera-do-natal.shtml, Acesso em 18 ago. 2020.
} 
Pode-se considerar o humor como uma forma de expressão artística, conceituando-se como uma manifestação voluntária com intuito de gerar comicidade, fazer graça. A priori, não existem temas proibidos pela ordem jurídica às manifestações humorísticas. Nesse aspecto, qualquer assunto pode ser objeto do humor, mesmo tramas delicadas ou que constituam tabus na sociedade, condição que apenas ratifica o caráter preferencial da liberdade de expressão frente a outros direitos fundamentais, conforme já decidido pelo Supremo Tribunal Federal no julgamento da ADI 4815/2015 $5^{14}$.

Essa tensão com assuntos sensíveis é própria da manifestação humorística e constitui sua matéria prima, seu insumo. São incontáveis as teorias que visam explicar o mecanismo do riso, mas a mais atual aponta para o fato de que o elemento central do humor é a surpresa, a percepção da quebra de paradigmas comportamentais, eis que "rimos do inesperado, do absurdo, do nonsense, do exagero. Rimos daquilo que viola nossas expectativas acerca de padrões comportamentais, e que nos parece subversivo da lógica ou da racionalidade" (ANDRADE, 2020, p. 93). A dificuldade intrínseca de se explanar o mecanismo do riso é de complexa elucidação, condição reconhecida até mesmo pelos estudiosos do tema ${ }^{15}$.

Em retorno aos tristes episódios narrados nos meados desta seção que envolvem o humor, sabe-se que a liberdade religiosa também é protegida pela Constituição Federal (art. $\left.5^{\circ}, \mathrm{VI}\right)$, contudo, mas não se pode conceber uma só pessoa imune ao sagrado direito da crítica, sobretudo quando advinda de um meio de comunicação polissêmico como o humor, expressão em que não necessariamente será obrigatório concordar com as premissas do gracejo para expressá-lo ou mesmo para dele rir (BENATAR, 2014). Não obstante o reconhecimento de que certas espécies de manifestações humorísticas podem fragilizar determinados grupos, expô-los ao ridículo ou mesmo gerar repulsa nas mais diversas camadas da sociedade, humor não se trata de opinião, mas de uma forma de expressão polissêmica e diversa, que só funciona se gozar de verdadeira liberdade para ser expressa.

\footnotetext{
${ }^{14}$ BRASIL, Supremo Tribunal Federal, Ação Direta de Inconstitucionalidade n. 4815/2015 DF. Disponível em: http://portal.stf.jus.br/processos/downloadPeca.asp?id=308558531\&ext=.pdf, Acesso em 10 dez. 2020.

${ }^{15}$ Conforma anota Elias Tomé Saliba (2018, p. 11). "[...] é preciso ter sempre presente que o tema do humor compõe uma autêntica galáxia, composta por incomensuráveis planetas de órbitas anárquicas: pode ser verbal, corporal, lúdico ou espetacular; pode exprimir uma experiência puramente subjetiva ou atender a propósitos comunicativos; pode nascer tanto de uma burla risível entre amigos quanto pode elevar-se a uma comédia de Molière; pode brotar espontaneamente como técnica de interação social ou profissional; pode gerar catarse ou catexia; enfim, pode servir tanto para cativar, ironizar, satirizar, parodiar, criticar, zombar, acariciar, desmoralizar - ou simplesmente para matar o tédio."
} 
Ridicularizar é uma forma característica de expressão; a sua substância não pode ser traduzida numa forma retórica menos ofensiva sem expressar algo muito diferente do que se pretendia. [...] Diz-se muitas vezes que a religião é especial porque as convicções religiosas das pessoas são tão centrais para as suas personalidades que não se deve pedir-lhes que tolerem quem ridiculariza as suas crenças, e porque podem sentir que têm o dever religioso de contra-atacar perante o que tomam como sacrílego. [...] Mas é a religião que tem de observar os princípios da democracia - e não o contrário. Não se pode permitir que religião alguma faça leis para todas as pessoas sobre o que se pode ou não desenhar, tal como não se pode permitir que possa fazer leis para toda a gente sobre o que se pode ou não comer. Nenhumas convicções religiosas podem sobrepor-se à liberdade que torna a democracia possível. (DWORKIN, 2006)

Sabe-se, por exemplo, que a liberdade humorística é uma ferramenta de grande valia para ser utilizada em face daqueles que abusam do poder, como tiranos e déspotas, sobretudo pelo caráter subversivo dessa espécie de expressão, eis que palavras lançadas em formas de piada são mais toleráveis do que aquelas lançadas com seriedade, em forma de opinião. $\mathrm{O}$ comediante sul-africano, Pieter Dirk Uys, por exemplo, satirizou a era do Apartheid e os políticos que a integravam com relativa impunidade (BENATAR, 2014).

Interessante intersecção entre a liberdade de expressão, o desenvolvimento social e a democracia pode se anotar quando "nenhuma fome coletiva substancial jamais ocorreu em nenhum país independente com uma forma democrática de governo e uma imprensa relativamente livre" (SEN, 2010, p. 201).

São muito os fundamentos jusfilosóficos em defesa da liberdade de expressão, justificativas de cunho utilitarista ou deontológico. Inserida no cunho utilitarista, a importância deste direito fundamental pode encontrar importância nos benefícios que produz para a coletividade, como aquele que se procurou dissertar um pouco a respeito nas linhas precedentes, a promoção da democracia e sua íntima ligação com o desenvolvimento social.

\section{CONCLUSÃO}

A liberdade econômica possibilita a cooperação voluntária entre os indivíduos em transações econômicas esclarecidas e que tragam mútuo benefício a ambos os lados, técnica de mercados que com menor ingerência estatal se mostra mais eficiente na consecução do objetivo de desenvolvimento social traçado pela Constituição Federal. A liberdade de expressão, por sua vez e em suas múltiplas funções, promove o ideal democrático, que quando 
presente em um país independente, evidencia sua resistência ao acometimento de mazelas coletivas substanciais. Compreende-se, dentro da perspectiva apresentada, que a ampliação da liberdade pode significar um meio para se alcançar o desenvolvimento social na medida em que esta garantirá ao indivíduo verdadeira autonomia.

A concepção de um Estado liberal pressupõe que a igualdade e o bem estar social são conquistados através do uso da liberdade, da ausência de interferências desnecessárias por parte do Estado nas relações interprivadas e em um abstenção de protagonismo do Estado no mercado. Fruto das conquistas liberais do final do século XVIII, a liberdade é um direito fundamental de primeira geração e ainda que possa ser ponderado com demais direitos da mesma hierarquia normativa, certamente frui de uma condição preferencial, eis que é pressuposto para o exercício de outros direitos fundamentais, como a possibilidade de associação e de participação no debate público, situação que evidencia ainda mais sua premência na busca pelo desenvolvimento social e na promoção do ideal democrático.

Poucos ideais foram tão perseguidos pela humanidade como a liberdade, cuja ausência limita a existência do indivíduo à servidão ou pior, à própria escravidão. Desenvolveu-se neste trabalho uma espécie de ode à liberdade, um voto de confiança a este direito fundamental. Fruto de lutas e reivindicações populares, a liberdade autentica os Estados verdadeiramente democráticos, cuja existência não pode ser sobrepujada por ideais religiosos, o que torna estes últimos suscetíveis de críticas nas mais variadas formas através, justamente, do gozo da plena liberdade de expressão.

É neste contexto delimitado da liberdade econômica e da liberdade de expressão que se inserem as reflexões aqui realizadas, de modo a demonstrar o quanto a fruição de tais irradiações deste direito fundamental podem contribuir para o desenvolvimento social e promover a democracia, contemplando uma pluralidade de individualidades e fomentando seu desenvolvimento em conjunto com a própria sociedade.

\section{REFERÊNCIAS BIBLIOGRÁFICAS}

AMARAL, Ana Claudia Corrêa Zuin Mattos do; HATOUM, Nida Saleh; HORITA, Marcos Massashi. O Paradigma Pós-Moderno Do Negócio Jurídico E A Necessidade De Uma Nova Concepção Na Contemporaneidade. Scientia Iuris, Londrina, v. 21, n. 2, p. 261-297, jul. 2017. DOI: 10.5433/2178-8189.2017v21n1p262. ISSN: 2178-8189. 
ANDRADE, André Gustavo Corrêa de, Liberdade de Expressão em tempos de cólera, 1. Ed., Rio de Janeiro, 2020

BARROSO, Luís Roberto, A dignidade da pessoa humana no direito constitucional contemporâneo: a construção de um conceito jurídico à luz da jurisprudência mundial, 4. Reimpressão - Belo Horizonte, Fórum, 2016.

BARBON, Júlia; ALBUQUERQUE, Ana Luíza, Sede do Porta dos Fundos é atacada com coquetéis molotov no Rio, Folha de São Paulo, São Paulo, 24 dez. 2019, Caderno Ilustrada, Disponível em: https://www1.folha.uol.com.br/ilustrada/2019/12/sede-do-porta-dos-fundossofre-ataque-a-bomba-na-vespera-do-natal.shtml, Acesso em 18 ago. 2020.

BASSETS, Marc, Governo francês renuncia à aposentadoria aos 64 anos após um mês de greves, El País, Madri, 11 jan. 2020, Caderno Internacional, Disponível em: <https://brasil.elpais.com/brasil/2020/01/11/internacional/1578760951_051980.html>, Acesso em 17 jan. 2021

Tribunal Condena a 30 anos de prisão o principal acusado do ataque contra o "Charlie Hebdo" em 2015, El País, Madri, 16 dez. 2020. Disponível em: $<$ https://brasil.elpais.com/internacional/2020-12-16/tribunal-condena-a-30-anos-de-prisao-oprincipal-acusado-do-ataque-contra-o-charlie-hebdo-em-2015.html>, Acesso em 18 jan. 2021.

BILLNER, Amanda; LINDEBERG, Rafaela; MAGNUSSON, Niklas, Now even swedes are questioning the wellfare state, Bloomberg Businessweek, Nova Iorque, 26 jun. 2018, Caderno Artigos, Disponível em: <https://www.bloomberg.com/news/articles/2018-0626/now-even-swedes-are-questioning-the-welfare-state>, Acesso em: 17 jan. 2021.

BENATAR, David, Taking Humour (Ethics) Seriously, But Not Too Seriously, Journal of Practical Ethics, Volume 2(1), Junho 2014.

BRANDÃO, Tom Alexandre, Rir e fazer rir: uma abordagem jurídica dos limites do humor, Indaiatuba, São Paulo, Editora Foco, 2018.

BRASIL, Supremo Tribunal Federal, Ação Direta de Inconstitucionalidade n. 4815/2015 DF. Disponível em:

$<$ http://portal.stf.jus.br/processos/downloadPeca.asp?id=308558531\&ext=.pdf $>$. Acesso em 10 dez. 2020.

CHRISAFIS, Angelica, Emmanuel Macron pledges to overhaul French welfare state, The Guardian, Londres, 9 jul. 2018, Caderno Mundo, Disponível em: $<$ https://www.theguardian.com/world/2018/jul/09/macron-pledges-to-overhaul-frenchwelfare-state>, Acesso em 17 jan. 2021. 
COSTA, Judith Martins. Os danos à pessoa no direito brasileiro e a natureza da sua reparação. São Paulo: Revista dos Tribunais, 2002.

CONHEÇA todos os vencedores dos prêmios nobel de economia, 2020, O Estado de São Paulo, São Paulo, 09 out. 2020, Caderno Economia, Disponível em: $<$ https://economia.estadao.com.br/galerias/geral,conheca-todos-os-vencedores-do-premionobel-de-economia,21786>, Acesso em 15 jan. 2021.

DWORKIN, Ronald, O direito de ridicularizar, The New York Review of Books, 23 mar. 2006. Tradução: Desidério Murcho para Crítica, Disponível em: <https://blogacritica.blogspot.com/2015/02/ronald-dworkin-o-direito-de.html> ou <https://www.nybooks.com/articles/2006/03/23/the-right-to-ridicule>, Acesso em: 12 set. 2020 .

FRIEDMAN, Milton, Capitalismo e liberdade, com ajuda de Rose D. Friedman; tradução Afonso Celso da Cunha Serra - 1. Ed, Rio de Janeiro: LTC, 2020.

GATEHOUSE, Gabriel, Suécia: país modelo ou nação em processo de falência?, BBC News Brasil, São Paulo, 15 set. 2018, Caderno Internacional, Disponível em: <https://www.bbc.com/portuguese/internacional-45506847>, Acesso em: 17 jan. 2021.

HOBBES, Thomas, Leviatã, São Paulo, Martins Fontes, 2003.

LOCKE, John, Dois tratados sobre o governo, São Paulo, Martins Fontes, 1998.

MARTINS NETO, João dos Passos, Fundamentos da liberdade de expressão, Florianópolis: Insular, 2008.

MICHAELIS. Dicionário Brasileiro da língua Portuguesa. 2021. Disponível em: $<$ https://michaelis.uol.com.br/busca? $\mathrm{r}=0 \& \mathrm{f}=0 \& \mathrm{t}=0 \&$ palavra=LIBERDADE $>$, acesso em 10 dez. 2020

MILTON, John, Areopagítica, Discurso pela liberdade de imprensa ao parlamento da Inglaterra, Rio de Janeiro, Topbooks, 1999.

MILL, John Stuart, 1806-1873, Sobre a liberdade Tradução: Pedro Madeira, Edições 70, 2018.

MINISTRO do STF censura sites e manda tirar do ar reportagem sobre Toffoli, Folha de São Paulo, São Paulo, 15 abr. 2019, Caderno Poder, Disponível em: 
$<$ https://www1.folha.uol.com.br/poder/2019/04/ministro-do-stf-censura-sites-e-manda-tirardo-ar-reportagem-sobre-toffoli.shtml>, Acesso em 05 fev. 2021.

PANSIERI, Flávio, Constituição, Economia e Desenvolvimento: Revista da Academia Brasileira de Direito Constitucional. Curitiba, vol. 8, n. 15, Jul-Dez 2016, ISSN 2177-8256.

PREVIDELLI, Fabio, Injustamente acusado de islamofobia: relembre o caso do professor decapitado na França, Aventuras na História, São Paulo, 10 mar. 2021, Caderno Notícias, Disponível em: https://aventurasnahistoria.uol.com.br/noticias/reportagem/injustamenteacusado-de-islamofobia-relembre-o-caso-do-professor-decapitado.phtml, Acesso em 18 mar. 2021.

ROUSSEAU, Jean-Jacques, Do contrato social, São Paulo, Martins Claret, 2003.

SALIBA, Elias Thomé, Crocodilos, satíricos e humoristas involuntários: ensaios de história cultural do humor - São Paulo: Intermeios; USP - Programa de Pós-Graduação em História Social, 2018.

SEN, Amartya, Desenvolvimento como Liberdade, São Paulo, Cia das Letras, 2010.

SARLET, Ingo Wolfgang, A eficácia dos direitos fundamentais, Porto Alegre, Livraria do Advogado, 2001.

STREECK, Wolfgang, As crises do capitalismo democrático, Tradução: Alexandre Morales, Novos Estudos CEBRAP, São Paulo, Edição 92, Volume 31, n. 1, março-2012, ISSN 0101-3300. 